\title{
Spiritual Well-being of Aging Japanese Survivors of Hansen's Disease: How Do Individuals Live Energetically Despite Having Experienced Extreme Situations?
}

\author{
Hitomi Yamao ${ }^{1}$, Masato Muguruma ${ }^{1}$, Kayoko Furochi ${ }^{2}$, Jyunko Mikami $^{1}, Y_{\text {Yumiko Tsuge }}{ }^{2}$ Makiko Kondo $^{3^{*}}$ \\ ${ }^{1}$ National Sanatorium OshimaSeisho-en, Takamatsu city, Kagawa prefecture, 761-0198, Japan \\ ${ }^{2}$ Former National Sanatorium OshimaSeisho-en, Japan \\ ${ }^{3 *}$ Graduate School of Health Sciences, Okayama University, Okayama, 700-8558 Japan
}

\begin{abstract}
Article Details
Article Type: Commentary Article

Received date: $30^{\text {th }}$ September, 2016

Accepted date: $05^{\text {th }}$ November, 2016

Published date: $10^{\text {th }}$ December, 2016

"Corresponding Author: Makiko Kondo, Graduate School of Health Sciences, Okayama University, Japan. E-mail: mkondo@, cc.okayama-u.ac.jp

Citation: Yamao H, Muguruma M, Furochi K, Mikami J, Tsuge Y, Kondo M (2016) Spiritual Well-being of Aging Japanese Survivors of Hansen's Disease: How Do Individuals Live Energetically Despite Having Experienced Extreme Situations?. J Comp Nurs Res Care 1: 105. https://doi.org/10.33790/jcnrc1100105.

Copyright: $\mathbb{C}^{2016}$, This is an open-access article distributed under the terms of the Creative Commons Attribution License 4.0, which permits unrestricted use, distribution, and reproduction in any medium, provided the original author and source are credited.
\end{abstract}

\begin{abstract}
Purpose: to clarify the spiritual well-being of aging survivors of Hansen's disease and explore the question "How do individuals live energetically despite having experienced extreme situations?"

Method: 1) participants: aging Hansen's survivors living in A sanatorium, living with vigor and liveliness, who were selected in a strict way. 2) Data collection: semi-structured interviews. 3) Analysis: qualitative and inductive methods.

Results: 1) characteristics of 5 selected survivors are relatively lower age, fewer unmarried, entered the leprosarium at teen-age, had held a managerial position in the sanatorium, fewer sequelae, and believed in religion, compared with all residents in A sanatorium. 2) narrative data was integrated the following 7 categories: $<1$. Continuing to have strong bonds with one's spouse and memory of parents' family $>,<2$. Healing sufferings by living in a sanatorium located on an island with a beautiful view $>,<3$. Possessing the self-confidence to overcome the difficulties $>,<4$. Living daily life with delight and worth even on a secluded island $>,<5$. Continuing one's efforts despite aging $>,<6$. Obtaining social approval $>$, and $<7$. Engaging in social interactions with the next generation and outside the island $>$.
\end{abstract}

Discussion: The spirituality of survivors of Hansen's disease had a trilaminar structure, comprising the following: 1) Establishing the existential foundation of a sustained self, 2) Living in the moment but contemplating the future as well. 3) Dovetailing within the society and transcending space and time. The participants had achieved the developmental task of ego integrity in old age. If compensatory mechanism is met, we might be able to develop an existential foundation for the sustained self and achieved ego integrity at old age despite having to live in unfortunate circumstances. Thus, if we support such individuals, we can promote compensatory mechanism.

Keywords: Spirituality, Hansen's disease, Aging, Narrative

\section{Introduction}

Why can humans live energetically despite having experienced extreme situations? Some adversities bringing existential suffering in our life, for example war, dispute, and poverty at the national level; and illness, losing one's job, divorce, bereavement, and cruelty at the personal level. The Buddha classified universal sufferings into groups of four and eight sufferings. The former includes fundamentally inevitable sufferings such as birth, aging, sickness, and death. The latter includes additional inevitable sufferings such as separation from a loved one, meeting people one dislikes, not getting what one seeks, and not being able to control one's mind and body [1]. When an individual faces adversity, he thinks "why do I face such adversity?" or "Does God exist?", feels that the situation is unreasonable, and experiences spiritual pain. Spiritual pain is actualized when we know about one's imminent death and others' death. Therefore, studies have been conducted by researchers and practitioners on end of life care and thanatology [2].

On the other hand, some people live energetically despite having experienced extreme situations. Viktor Emil Frankl [3], who developed Logotherapy and existential analysis methods after being released from Auschwitz, propounded "the Will to Meaning," according to which we can discover meaning in life in three different ways: by creating work or doing a deed, by experiencing some things or encountering someone, and by our attitude toward unavoidable suffering. In the third method, we can find meaning in life even if we cannot assure life tomorrow. Friedrich Nietzsche [1] put forth the concept of "Ubermensch" as the ideal man of the future. According to him, the Ubermensch will live endure the nihilism of eternal return, which means repeating same things unreasonably and forever, love his own destiny, become the creator of new worth, and live strongly. Some dying patients can accept their destiny affirmatively and foresee a peaceful death, or philosophize about the meaning of life by knowing about their imminent death. This is called spiritual wellbeing. Spiritual wellbeing is evidenced by quality of life (QOL), which is measured in three areas; physical, mental, and social. The QOL of dying patients decreases as their death approaches, but when the QOL is measured across four areas, i.e., physical, mental, social, and spiritual, 
the QOL of such patients does not always decrease as death approaches [4].

Spirituality is the foundation of our search for meaning in life. It related to human existence and is possessed by all individuals [2]. According to WHO, the concept of spirituality is essential to that of QOL and human dignity. According to Haas' QOL model [5], QOL is defined in terms of physical, psychological, social, and spiritual wellbeing. According to lists of nursing diagnosis by North American Nursing Diagnosis Association (NANDA) [6], both spiritual pain and the readiness for enhanced spiritual well-being belong to the domain of life principle. According of Kawa [7], spirituality is the foundation of human existence, but it pertains to the relationship with something greater than the self, for example God, the cosmos, nature, and so on. On the other hand, from the perspective of the self, it focuses on the existence searching for the meaning of life. Spirituality is similar to religion, but they are not the same. Spirituality is often not actualized in daily life, except by deeply religious people. On the other hand, when we meet hardships in life, it appears as spiritual pain, and when person experiencing hardships accepts or assumes a philosophical view of his destiny, he feels peace of mind and notices the existence of spirituality as spiritual well-being. Spiritual well-being is good condition of spirituality, and is defined as connecting the self, others, and something greater than the self over time.

Additionally, it pertains to the search for meaning in life and affirmation of one's life despite hardships [8]. According to Misawa [9], for the elderly, spirituality measurements include concepts such as reviewing one's life, relationship with others, interest in the transcendent, pursuing one's being, and focusing on the future. Takeda [10], suggested that it includes the meaning and purpose of living, attitudes toward death and dying, self-transcendence, compassion for others, spiritual support, and harmony with the nature.

Everyone cannot avoid hardships in life; therefore, it is important to think about ways to overcome the hardships, and to live vividly and without despair. In Japan, several persons have experienced hardships in life. Hansen's disease[11] is caused by Mycobacterium Leprae, and it mainly affects the periphaeral nerves. In this disease, motor nerve paralysis causes deformation of the limbs and face, while sensory nerve paralysis leads to loss of pain sensations, which in turn increases the individual's susceptibility to experiencing severe injuries such as osteomyelitis and loss of limbs. Additionally, owing to direct infiltration or lagophthalmos, individuals with Hansen's disease experience facial nerve paralysis and loss of eyesight. They exhibit features such as flat nose or saddle nose, and loss of eyebrows and hair.

Existence of patients with Hansen's disease has been reported in the oldest civilizations of China, Egypt, and India. They often faced discrimination because people thought that the changes in physical appearance occurred as a punishment by God $[12,13]$. In modern times, Dr. Hansen discovered Mycobacterium Leprae in 1873, and isolation of patients was promoted for the prevention of a worldwide epidemic. In Japan, the old government considered Hansen's disease and its patients as a national disgrace, and adopted forced and lifelong isolation even during national crises such as World War II. There was a shortage of doctors and nurses in leprosariums; therefore, such facilities were often maintained by the patients themselves, for example patients engaged in the nursing of severe patients, construction, washing clothes, conducting funerals, etc. [14-15]. Because patients with sensory nerve paralysis were more susceptible to injuries during forced labor, and because they were forced to work in a bad environment in order to survive in severe poverty, their injuries often worsened beyond osteomyelitis, and they subsequently lost a limb [16].

Following the development of the silver bullet Promin, many countries started reevaluating their policy of isolation, as recommended by WHO. However, lifelong isolation was continued in Japan based on the opinions of leading scholars [17]. Long life and forced isolation were mitigated on-site, but the law on lifelong isolation was continued to be implemented until 1996. Thus, survivors of Hansen's disease lost the opportunity for rehabilitation into the society. The government, the national congress, and the judiciary apologized to the survivors and provided compensation.

Now most of the survivors of Hansen's disease live in thirteen national sanatoriums. Their average age is 83.4 years, and, among them, about 139 deaths occur each year old. In 2014, there were 1840 residents across all sanatoriums in the country [18]. In this population, the number of those dependent on care is increasing due to dementia, physical malfunction with aging, chronic disease, and Hansen's disease sequelae. In A Sanatorium, where the present study was conducted, in $2014,32 \%$ of the residents were reported to have dementia [18]. However, some residents can still lead their life with vigor and liveliness. By clarifying the spiritual well-being of aging survivors of Hansen's disease who had experienced sufferings, we can attempt to answer the question raised in the beginning of this paper, "How do some individuals live energetically despite having experienced extreme situations?"

This study is significant in terms of four issues. First, it attempts to seek a universal answer to the above question. Second, Hansen's disease is not the only illness that attracts stigma. People have negative attitudes toward several diseases which have an unknown cause, have high fatality rates or are incurable, and have changing features, for example Ebola hemorrhagic fever. Patients of such diseases are also ostracized like the patients of Hansen's disease were before World War II. An understanding of the strengths of survivors of Hansen's disease who overcame stigma can be applied to future patients with unknown diseases that attract stigma. Third, in Japan, almost all cases of Hansen's disease occurred before World War II, will very few new patients. Additionally, survivors of the disease do not have children because the earlier government conducted vasectomies to deracinate Hansen's disease. Thus, the survivors of the disease are aged, and the history of Hansen's disease in Japan is expected to end with their death. Therefore, we must pass on their experiences. Fourth, Hansen's disease is often discussed due to its negative history, for example discrimination and prejudice in the society, and bioethical problems related to the medical policy or administration of sanatoriums. However, survivors have strength and wisdom that can be acquired only by persons who have experienced and overcome extreme situations. We believe that nurses working in such sanatoriums must pass down not only the negative history but also the survivors' wisdom and strength, because the latter would promote the recovery and reinstatement of dignity in survivors of other stigmatized diseases.

\section{Purpose}

The purpose of this study was to clarify the spiritual well-being of aging survivors of Hansen's disease in Japan and to discuss the wisdom and strength of persons who have experienced extreme situations.

\section{Methods}

1. Subjects: We followed the following process to select survivors of Hansen's disease who lived with vigor and liveliness. First step: Research members, who were nurses at A Sanatorium, selected candidates who resided in A Hansen's disease sanatorium, did not have a cognitive disorder, and lived with vigor and liveliness. Second step: We conducted research meetings to discuss the suitability of candidates, and excluded candidates from the sample if there was an objection from even one researcher. Third step: The candidates' consent to participate was sought.

2. Data collection: A semi-structured interview was conducted. The researcher listened to and empathized with the subjects' accounts. 
Questions were sometimes added to clarify the subjects' meaning. Subjects' accounts were recorded and verbatim transcripts were created with their permission. The interview guide comprised the following questions: 1) What supports your life? 2) What do you enjoy in your life? 3) What enables you to live with vigor and liveliness?

3. Data analysis: A qualitative and inductive analysis was performed using the following steps, to understand the meaning behind the perspectives of the subjects: 1) Individual analysis: a) reading the verbatim transcripts thoroughly, identifying reports about clinical nursing competency, and expressing the meaning in one sentence; $b$ ) grouping sentences with similar meanings, expressing the meaning of all the grouped sentences, and creating labels. 2) Whole analysis: a) reading all labels thoroughly, gathering similar labels, expressing the meaning, and creating categories; b) continuing these processes, increasing the level of abstraction, and creating subcategories and categories. 3) Ensuring the authenticity and validity of the results: a) during the research process, supervision by a qualitative researcher; b) confirmation from subjects about whether the categories and subcategories captured their intended meaning correctly.

4. Ethical considerations: Subjects were informed that their participation was voluntary, that the data would be kept confidential and used only in the present study, and that they were free to decline to answer questions or provide information. The research objectives and procedures were also described to the subjects. Consent was obtained from all subjects orally and in writing. The research proposal was approved by the ethics committee of the National Sanatorium Oshima-Seisho-en (Authorization number: H26-1).

\section{Results}

1. Subject characteristics: The candidate selecting process yielded eighteen survivors as initial candidates from the 77 survivors residing in A Sanatorium in August 2014. Following researcher meetings, nine candidates were excluded and four others did not agree to participate because three of them were busy and one person was unwell. Finally five survivors were selected as participants.

Details of the subjects' characteristics have been shown in Table 1. The average age of the subjects in this study was 78.8 years, and that of all the 77 residents at A Sanatorium was 82.0 years. Three out of the five subjects were male and two were female, while amongst all the residents of the sanatorium, 40 were male and 37 were female. In terms of marital status, 3 of the subjects $(60 \%)$ were married, 1 subject was widowed (20\%), and 1 subject was divorced (20\%). Amongst all the 77 residents, 28 persons were married (36.4\%), 32 persons were widowed (41.6\%), 3 persons were divorced (3.9\%), and 14 persons were unmarried (18.2\%). The average age at which the five subjects entered the sanatorium was 15.8 years, and the average duration spent in the sanatorium was 63.5 years. In terms of social roles, 3 subjects currently held some positions in the sanatorium, while 2 subjects had retired; however, all five of them had held a social role on the island in the past. About sequelae related to Hansen's disease, contracture was observed in three subjects, neuralgia in three subjects, and hypoesthesia in all five subjects, while none of them had lost their eyesight. All subjects were independent in terms of activities of daily living and believed in religion.

As evident from the above, the subjects of this study showed characteristics such as relatively lower age, fewer unmarried, entered the leprosarium at teen-age, had held a managerial position in the sanatorium, fewer sequelae, and believed in religion.

\begin{tabular}{|c|c|c|c|c|c|c|c|c|c|c|c|c|}
\hline \multirow[t]{2}{*}{ Case } & \multirow[t]{2}{*}{ Sex } & \multirow[t]{2}{*}{$\begin{array}{l}\text { Age } \\
\text { (years) }\end{array}$} & \multirow{2}{*}{$\begin{array}{l}\text { Age at } \\
\text { admission } \\
\text { into the } \\
\text { sanato- } \\
\text { rium } \\
\text { (years) }\end{array}$} & \multirow{2}{*}{$\begin{array}{l}\text { Years } \\
\text { living } \\
\text { in the } \\
\text { Sanato- } \\
\text { rium }\end{array}$} & \multirow[t]{2}{*}{$\begin{array}{l}\text { Marital } \\
\text { status }\end{array}$} & \multicolumn{2}{|c|}{$\begin{array}{l}\text { Social role (in the } \\
\text { sanatorium) }\end{array}$} & \multicolumn{5}{|c|}{ Sequelae of Hansen's disease } \\
\hline & & & & & & former & At present & $\begin{array}{l}\text { Hypoes- } \\
\text { thesia }\end{array}$ & $\begin{array}{l}\text { Neura- } \\
\text { lgia }\end{array}$ & $\begin{array}{l}\text { Motor- } \\
\text { distur- } \\
\text { bance }\end{array}$ & $\begin{array}{l}\text { Loss } \\
\text { of } \\
\text { eye- } \\
\text { sight }\end{array}$ & $\begin{array}{l}\text { Reli- } \\
\text { gion }\end{array}$ \\
\hline A & Male & 72 & 13 & 59 & Divorced & $\begin{array}{l}\text { Vice- } \\
\text { president } \\
\text { of the } \\
\text { residents' } \\
\text { association, } \\
\text { chief of } \\
\text { the aging } \\
\text { society, } \\
\text { vice-chief } \\
\text { of the } \\
\text { Japanese } \\
\text { croquet } \\
\text { team, chief } \\
\text { of the } \\
\text { Karaoke } \\
\text { club, etc }\end{array}$ & $\begin{array}{l}\text { Chief of the } \\
\text { aged society, } \\
\text { chief of the } \\
\text { association } \\
\text { of people } \\
\text { from the } \\
\text { same } \\
\text { prefecture, } \\
\text { chief of the } \\
\text { Japanese } \\
\text { croquet team }\end{array}$ & $\begin{array}{l}\text { Left } \\
\text { hand and } \\
\text { forearm, } \\
\text { left foot }\end{array}$ & None & None & None & $\begin{array}{l}\text { Budd- } \\
\text { hism }\end{array}$ \\
\hline B & Male & 78 & 16 & 62 & Married & $\begin{array}{l}\text { Chief of } \\
\text { the aging } \\
\text { society, } \\
\text { vice-chief } \\
\text { of the aging } \\
\text { society, } \\
\text { chief of the } \\
\text { religious } \\
\text { party }\end{array}$ & $\begin{array}{l}\text { Vice- } \\
\text { president of } \\
\text { the residents' } \\
\text { association, } \\
\text { vice-chief of } \\
\text { the religious } \\
\text { party }\end{array}$ & $\begin{array}{l}\text { Both } \\
\text { hands } \\
\text { and } \\
\text { forearms, } \\
\text { right foot }\end{array}$ & $\begin{array}{l}\text { Hand } \\
\text { and } \\
\text { forearm, } \\
\text { foot4- } \\
\text { 5times/ } \\
\text { year, } \\
\text { change- } \\
\text { of } \\
\text { seasons) }\end{array}$ & None & None & $\begin{array}{l}\text { Budd- } \\
\text { hism }\end{array}$ \\
\hline
\end{tabular}




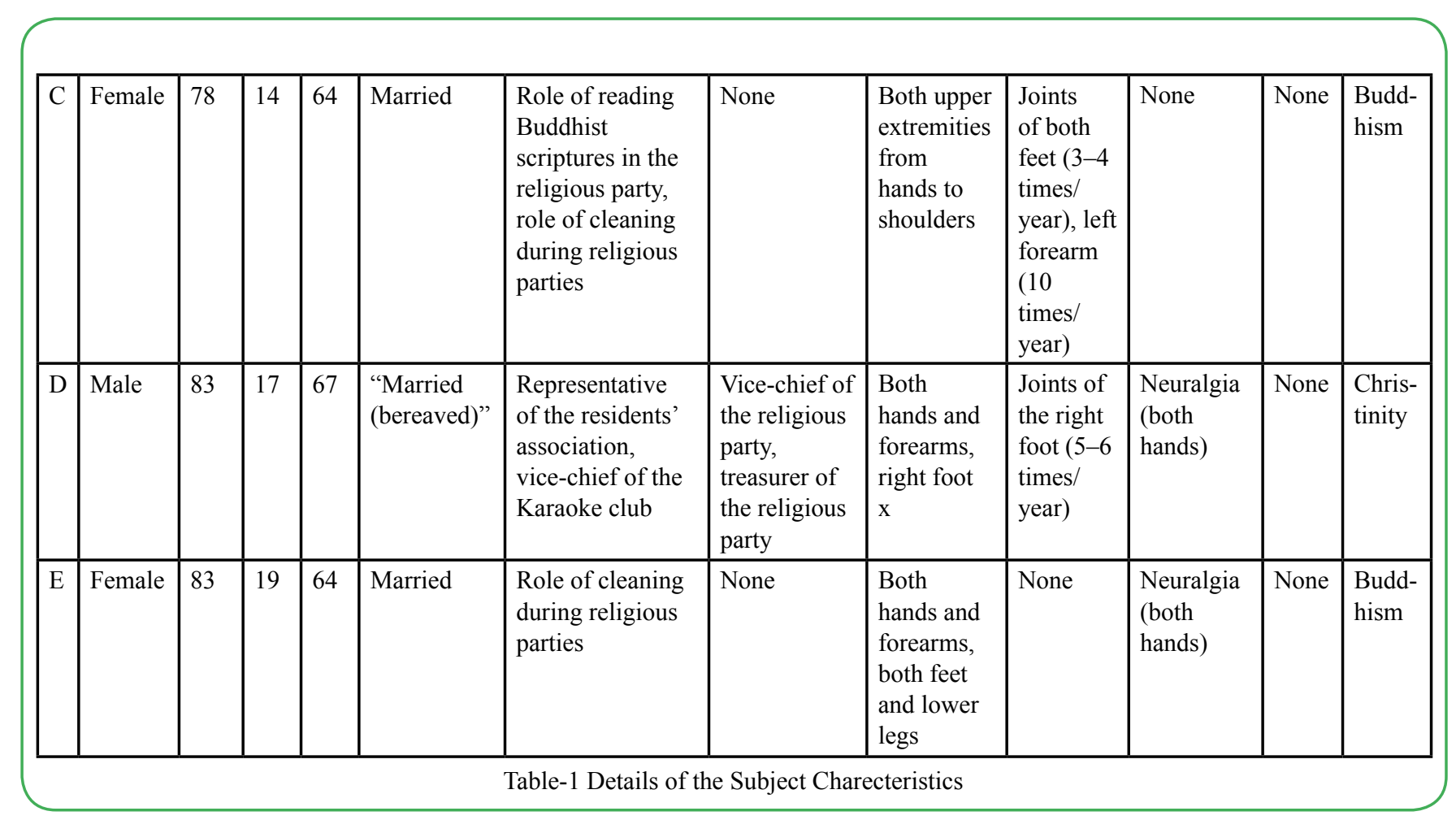

\section{Spiritual well-being of aging survivors of Hansen's disease in Japan}

The interviews lasted from 32 minutes to 1 hour 54 minutes (average time 1 hour 11 minutes) per subject. Data collected from the five subjects were integrated into 25 subcategories and 7 categories. The validity of the analysis was confirmed by the subjects. The $<$ categories $>,<<$ subcategories $>>$, and details of the same have been presented in Table 2.

1) $<$ Continuing to have strong bonds with one's spouse and memory of parents' family>

This category contained the following five subcategories: $<<1$ ) I have memories of my parents, who could interact despite having Hansen's disease $>>$; $<<2$ ) I have memories of my parents protecting me from discrimination and persecution $>>;<<3$ ) I have memories of choosing to go to the leprosarium and cut off from my deep affections for my family to protect them from discrimination and persecution $>>$; $<<4$ ) I could not understand my mother's deep affection, but now I can understand it $>>$; and $<<5$ ) I shared a deep bond and affection with my spouse because we could not go out into the society and had to live only in the sanatorium $>>$.

2) $<$ Healing sufferings by living in a sanatorium located on an island with a beautiful view>

This category contained the following three sub categories: $<<6$ ) Living in a sanatorium is better than living in the society, because the former does not attract discrimination and prejudice $>>;<<7$ ) I could adapt to living in a sanatorium because I was admitted here when I was a child. At that time, I knew nothing about the society and did not have any ambitions $>>$; and $<<8$ ) I was healed by the beautiful view of the sea and islands (Sanatorium A is located on a small island) $>>$.

\section{3) $<$ Possessing the self-confidence to overcome the difficulties $>$}

This category contained the following four sub categories: $<<9$ ) I am bright and positive. Therefore, I can overcome problems $>>$; $<<10$ ) I have learnt life lessons that encourage me $>>$; $<<11$ )I am self-confident because we overcame poverty and World War II $>>$; and $<<12$ ) I am satisfied with my present life because we won justice and have a comfortable life as compared to the enforced work and miserable life of the past $>>$.

\begin{tabular}{|c|c|}
\hline \multicolumn{2}{|c|}{$<$ Categories $>$} \\
\hline$<<$ Subcategories $>>$ & One example among many codes \\
\hline \multicolumn{2}{|c|}{$<1$. Continuing to have strong bonds with one's spouse and memory of parents' family $>$} \\
\hline \multirow[t]{4}{*}{$\begin{array}{l}<<1 \text { ) I have memories of my parents, who could interact despite } \\
\text { having Hansen's disease. }>>\end{array}$} & $\begin{array}{l}\text { - I forgave to come back home only once a year. I drank alcohol } \\
\text { with my mother. It was very delicious, I cannot remember it. }\end{array}$ \\
\hline & $\begin{array}{l}\text { - As a child, I was shy and clumsy, and did not receive } \\
\text { praise from my mother. When I made small wooden ship in } \\
\text { sanatorium my mother was surprised to see it and praised me. }\end{array}$ \\
\hline & $\begin{array}{l}\text { - Although my mother had seasickness, she continued to come } \\
\text { to meet me on the island until her death. }\end{array}$ \\
\hline & $\begin{array}{l}\text { My mother and I waited expectantly for letters from each } \\
\text { other. }\end{array}$ \\
\hline
\end{tabular}

Table. 2 Cont...... 
$<<2$ ) I have memories of my parents protecting me from discrimination and persecution. $>>$
My mother thought, "I cannot die and must live as long as possible because my son lost the place coming back by my death, if he is forgiven to go out leprosarium." She worked on a mandarin plantation until the age of 100 years. When I was suffering, I was supported by my mother's thinking.

- When I had to go to the leprosarium, my mother chased my bus on foot like crazy. Now I cannot forget it and this memory sustains me.

- My mother said, "If you would go to the leprosarium, you would face many difficulties, so you must not go to the leprosarium." She prepared a small washtub for my bath in order to prevent spreading the leprosy infection to other family members.

- I give my father about compensation from nation, because I think he faced difficulties due to my Hansen's disease. But my father could not use the money; he said "I cannot use the money I receive as compensation for my son's sufferings and difficulty."

- When the villagers noticed my disease and banished me from my home town, my mother stormed to visit the village head and tried to protect me, her face was like a demon.

$<<3$ ) I have memories of choosing to go to the leprosarium and cut off from my deep affections for my family to protect them from discrimination and persecution.>>

- If I stayed at home, my older sister's engagement may have been broken off by my Hansen's disease. So I decided to go to the leprosarium and left home despite the heartbreak.

- My brother's wife hated Hansen's disease. I felt my brother was ashamed of me and pitied me, so I decided to have my name removed from the family register.

- My mother admonished me, "You might face a lot of difficulty in the leprosarium, but your brothers and sisters have had to face difficulties in the society."

$<<4$ ) I could not understand my mother's deep affection, but now I can understand it. $>>$

$<<5$ ) I shared a deep bond and affection with my spouse because we could not go out into the society and had to live only in the sanatorium. $>>$

As a child, I could not understand my mother's real intentions, because my mother confined me to the house. I often thought that she might be my stepmother. Now I can understand her real intentions; she loved me deeply, and protected me from the society, and tried to prevent forced isolation.

- When I realized that I would not be able to come back home and accepted the fate that I had to live this way all my life, I met my wife and we were married. We have lived together and have supported each other since then.

- My wife is straightforward, and I am resilient. We are very compatible; therefore, we have gotten along well for a long time.

- As a wife, I want to care for my husband till he is in his deathbed.

$<2$. Healing sufferings by living in a sanatorium located on an island with a beautiful view $>$

$<<6$ ) Living in a sanatorium is better than living in the society, because the former does not attract discrimination and prejudice. $>>$

$<<7)$ I could adapt to living in a sanatorium because I was admitted here when I was a child. At that time, I knew nothing about the society and did not have any ambitions.>>
When I lived at home, I could not go out as I would face discrimination and forced isolation in a leprosarium. But on joining a leprosarium, I could go out and bask in sunshine for the first time. I felt glad.

- Older patients were affectionate and tender. I was glad and was healed from the bitter experiences that I had while living out of the island.

- I entered the sanatorium without experiencing working in the society and without knowledge about the society's common sense. So I did not have questions and doubts regarding the life at the sanatorium and I thought that was how it was. So my difficulties were less as compared to those of a person who had experienced life in a society.

Table. 2 Cont 


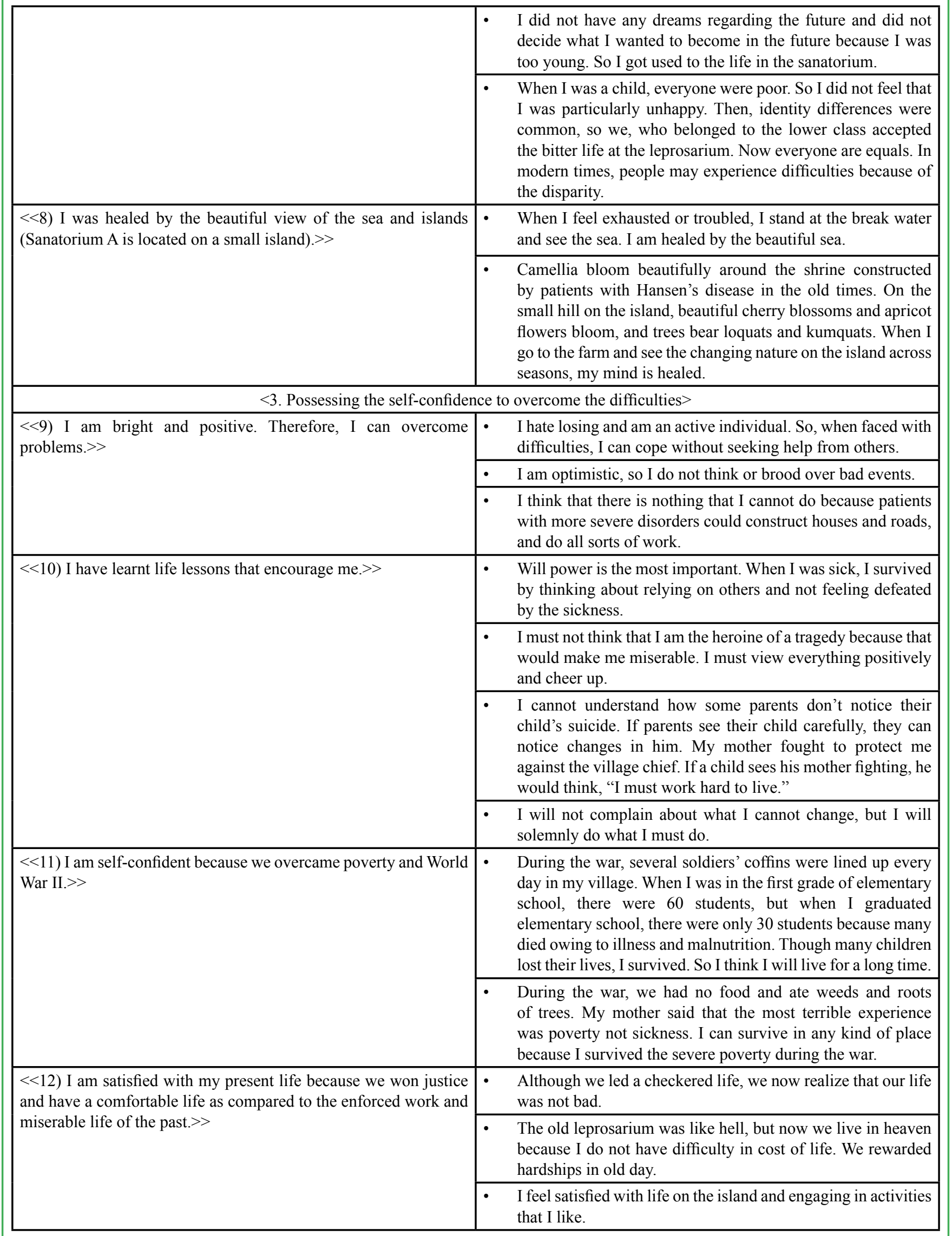

Table. 2 Cont. 
$<4$. Living daily life with delight and worth even on a secluded island $>$

\begin{tabular}{l|lc}
$<<13)$ I feel joyful and worthy when I cherish my spouse. $>>$ & $\cdot \quad$ I liked playing gate ball but my wife did not play it because
\end{tabular} she was blind. So I stopped playing gate ball and started singing with my wife.

- I cultivate many tomatoes because she likes them and eats only tomatoes at breakfast.

- When I stood on stage to introduce the movie in which I was the protagonist, my wife was waving to me. I did not notice it then, but when I saw the film later, I noticed her behavior and felt that she loved me.

$<<14$ ) I feel joyful and worthy while interacting with people on the island, such as fellow survivors, nurses and nurse assistants, and children of the sanatorium's staffs whose school is on the island.>>
While growing vegetables on the farm, I enjoy communicating and competing with friends of survivors who like growing farm products.

- If I cannot visit the farm due to other engagements, my farming friends worry and call out to me.

- My wife was introduced by a senior member of the residents' self government association. I was glad it because I felt that I was accepted by the senior member.

- When I developed and published a CD of my songs, medical and welfare staffs and their children who lived on the island cooperated by ensuring a silent environment to avoid noise during the recording.

$<<15$ ) I feel joyful while eating. $>>$

- After farm work, dinner is very delicious. I am happy.

- If I hear about delicious breads, I will go and buy them even if the shop is far away.

$<<16$ ) Because I must live on a secluded island and feel stifled, I engage in activities to release my energy. $>>$

- Though there are only a few things to do on the island, I continue to find enjoyable activities. For example, I was fascinated with fishing and even made a ship. Now I am fascinated with Bonsai, in which I made a shaped pine. Because I love Bonsai and do not want to kill the plant, I go to water it even when I am unwell.

- I enjoy having to do what needs to be done every day. So I work in the field, but in a staggered way. If I do all the work on one day, I will have nothing to do on another day.

- I am unexpectedly busy, I have many hobbies; Karaoke singing, gate ball, calligraphy, and comic haiku.

$<5$. Continuing one's efforts despite aging $>$

$<<17)$ I invest effort in maintaining health and independence in daily life. $>>$
- I stay healthy by engaging in farming.

- I ensure that I do not disturb my daily schedule.

- $\quad$ Now I am aging, I continue to do stepping exercises every day to avoid being bedridden and do numerical calculations to prevent dementia.

- After surgery, I did not rely on others so that I could expedite my recovery.

- I dislike hemodialysis because it is constraining. But I accepted hemodialysis in order to live a healthy life.

$<<18$ ) I will continue to learn because I could not learn in childhood because of poverty and discrimination. $>>$
As a child, I could not go to school because I was discriminated against owing to Hansen's disease. I could not study after entering the leprosarium owing to insufficient facilities, for example, another patient was the teacher. Now I am happy to learn as I have a lot of free time and can live without having to work.

- $\quad$ Every morning, I read each nook and corner of the newspaper and I can know about the events occurring in the world. Knowing the world is very interesting for me. 
$<6$. Obtaining social approval $>$

$<<19)$ I play several roles in the sanatorium and shoulder $\cdot$ I have the role of a storyteller of Hansen's history and our responsibilities. $>>$ experiences, and I and responsible for telling these stories to visitors coming from outside the island, who wish to learn about human rights.

- Many residents depend on me and I undertake several responsibilities such as being the chief of the residents' association or association of people from the same prefecture.

- I volunteer to care for residents with multiple severe disorders.

$<<20)$ I am glad to be praised for our products like vegetables, draft trees in pots, and small ships. $>>$

A Bonsai made by me was displayed in the hall in the prefecture office, and I was commended for it. I feel glad and encouraged on receiving acknowledgement from many people in public.

- I am very glad that a professional ship maker praised the small ship I made.

$<7$. Engaging in social interactions with the next generation and outside the island $>$

$<<21$ ) Communication with relatives included not only my parents and siblings but also my sibling's spouse, nephew, and niece.>>
$<<22$ ) Though my interaction with the society was broken off, my social interactions and activities started again and increased due to my spouse's encouragement. $>>$
Owing to my mothers' efforts, I could come back home and I drank alcohol with my brothers and sisters. My relationship with them continues despite my mother's death. I am very glad.

- My nephew and niece said that they will continue to perform a memorial service after my death. I am very glad and feel at ease.

- My sister informed her husband about my disease even though I had told her not to. Later, her husband visited me and called me "my old sister" and became attached to me. Even their children do not hate me and eat rice from the same pot.

- I started singing by recommending herm, although I was very hesitant about singing before others and thought that I would not be able to do it. After I started singing, I travelled all over the country with my wife to attend recitals of singers at other sanatoriums. I was very happy that I did not go out of the leprosarium.

- My relationship with my family was broken off due to Hansen's disease, so I continued to feel lonely. But my wife had many friends and continued to stay in touch with her school mate who lived off the island. I interacted with them too and my loneliness decreased. When I had to pull out my name from the family register to protect my family from discrimination, my wife entered my name into her family register. Now I am grateful to her.

$<<23$ ) Owing to outsiders who do not discriminate, I have opportunities to interact with the society, and, for some time, I forget that I am a "survivor of Hansen's disease.” >
- When I attend a networking event with relatives in my hometown once a year, a nurse who resigned long ago accompanies me and cares for me, and the landlady at the inn entertains me like an old friend. I feel very glad.

- $\quad$ Event staff cook food using the vegetables I cultivated and sell it to the general customer participating in the event. When the general public willing eat vegetables grown by a survivor of Hansen's disease, I feel very happy

- During forced isolation, patients' area and healthy persons' area was divided and patients could not enter the healthy person's area. Despite discontinuing isolation and starting human exchanges such as playing gate ball with people from outside the sanatorium, gate ball players wore gloves to avoid touching the grip held by a survivor of Hansen's disease and later disposed the gloves. When I saw this, I felt that they considered us dirty. Now many people visit the island to learn about human rights. They are glad to go fruit picking in my field. I feel very happy when I see this.

Table. 2 Cont... 


\begin{tabular}{|c|c|}
\hline \multirow[t]{3}{*}{$\begin{array}{l}<<24) \text { Our supporters' children have become our new supporters, } \\
\text { thus continuing the work across generations. }>>\end{array}$} & $\begin{array}{l}\text { - A Catholic priest taught me hymns, and I started singing. The } \\
\text { priest's daughter who visited the sanatorium with the priest } \\
\text { as a child is now a singer. Recently, after she visited and sang } \\
\text { here, I published a CD containing my songs based on her } \\
\text { training and recommendation. }\end{array}$ \\
\hline & $\begin{array}{l}\text { A volunteer who visited the sanatorium as a university student } \\
\text { now brings his wife and children along. }\end{array}$ \\
\hline & $\begin{array}{l}\text { - A movie was made on me and my spouse, and it was screened } \\
\text { on TV. I am glad that the general public know about the } \\
\text { existence of such couples, who lived with Hansen's disease. }\end{array}$ \\
\hline \multirow[t]{2}{*}{$\begin{array}{l}<<25) \text { I could be known as a person living with Hansen's disease } \\
\text { and my interactions with those outside the island could increase } \\
\text { because the press or media would want to report my experience } \\
\text { with Hansen's disease. }>>\end{array}$} & $\begin{array}{l}\text { ACatholic priest living far away watched the movie and visited } \\
\text { me. My wife and I are the movie's protagonists. Becoming } \\
\text { relationship with the movie, the priest marriage votary living } \\
\text { in local. I felt happy to be invited to their wedding, and now } \\
\text { their children visit me. }\end{array}$ \\
\hline & $\begin{array}{l}\text { - Because my brother's wife hated Hansen's disease, my } \\
\text { relationship with him was cut off. She watched my movie on } \\
\text { TV. I am very glad that this movie has a large impact on those } \\
\text { who hate Hansen's disease. }\end{array}$ \\
\hline
\end{tabular}

Table 2: Spiritual well-being of aging survivors of Hansen's disease in Japan

\section{4) $<$ Living daily life with delight and worth even on a secluded island $>$}

This category contained the following four sub categories: $<<13$ ) I feel joyful and worthy when I cherish my spouse $>>$; $<<14$ ) I feel joyful and worthy while interacting with people on the island, such as fellow survivors, nurses and nurse assistants, and children of the sanatorium's staffs whose school is on the island $>>$; $<<15$ ) I feel joyful while eating $>>$; and $<<16$ ) Because I must live on a secluded island and feel stifled, I engage in activities to release my energy $>>$.

\section{5) <Continuing one's efforts despite aging >}

This category contained the following two sub categories: $<<17$ ) I invest effort in maintaining health and independence in daily life $>>$ and $<<18$ ) I will continue to learn because I could not learn in childhood because of poverty and discrimination $>>$.

\section{6) < Obtaining social approval>}

This category contained the following two sub categories: $<<19$ ) I play several roles in the sanatorium and shoulder responsibilities $>>$ and $<<20$ ) I am glad to be praised for our products like vegetables, draft trees in pots, and small ships $>>$.

\section{7) $<$ Engaging in social interactions for the next generation and} outside the island $>$

This category contained the following five subcategories: $<<21$ ) Communication with relatives included not only my parents and siblings but also my sibling's spouse, nephew, and niece $>>$; $<<22$ ) Though my interaction with the society was broken off, my social interactions and activities started again and increased due to my spouse's encouragement $>>$; $<<23$ ) Owing to outsiders who do not discriminate, I have opportunities to interact with the society, and, for some time, I forget that I am a "survivor of Hansen's disease" $>>$; $<<24)$ Our supporters' children have become our new supporters, thus continuing the work across generation $>>$; and $<<25$ ) I could be known as a person living with Hansen's disease and my interactions with those outside the island could increase because the press or media would want to report my experience with Hansen's disease $>>$.

\section{Discussion}

The spiritual well-being of aging survivors of Hansen's disease comprised 7 categories. In this section we discuss about 1) the essential meanings and structure of spirituality in them,
2) suggestions derived from the experiences of survivors of Hansen's disease to explain the question put forth in the beginning of this paper, "How do individuals live energetically despite having experienced extreme situations?", and 3) the limitations of the study.

The essential meanings and structure of spirituality in aging survivors of Hansen's disease

The structure of spiritual well-being of the subjects has been presented as a three-layer structure, as illustrated in Figure 1.

\section{1) Establishing the existential foundation of the sustained self}

Three categories; $<1$. Continuing to have strong bonds with one's spouse and memory of parents' family $>,<2$. Healing sufferings by living in a sanatorium located on an island with a beautiful view $>$, and $<3$. Possessing the self-confidence to overcome the difficulties $>$ showed that the survivors had acquired an existential foundation for the sustained self by achieving the developmental tasks of each stage, as proposed by Erik Erikson. They had achieved ego integrity, which is the developmental task for old age. The existential foundation constitutes the core of personality formation.

\section{(1) Trust versus mistrust}

According to Erik Erikson [19], individuals have to achieve certain developmental tasks in each stage of their lifespan. Thus, the individual can acquire basic virtues by conquering psychosocial crises. The psychosocial crisis at infancy is trust versus mistrust, and the basic virtue is hope. On getting satisfactory affection from the mother at infancy, he realizes that it is safe to trust other people, and had hope in the world. His world expands from his mother and family to the society. If we cannot develop trust, we might have trouble in developing relationships with others, not only in adolescence, but also in adulthood.

$<1$. Continuing to have strong bonds with one's spouse and memory of parents' family $>$ had five subcategories, four out of which, i.e., $<<1)$ I have memories of my parents, who could interact despite having Hansen's disease $>>$; $<<2$ ) I have memories of my parents protecting me from discrimination and persecution $>>$; $<<3$ ) I have memories of choosing to go to the leprosarium and cut off from my deep affections for my family to protect them from discrimination and persecution $>>$; and $<<4$ ) I could not understand my mother's deep affection, but now I can understand it $>>$ show that the survivors had memories of being loved by their family not only during 


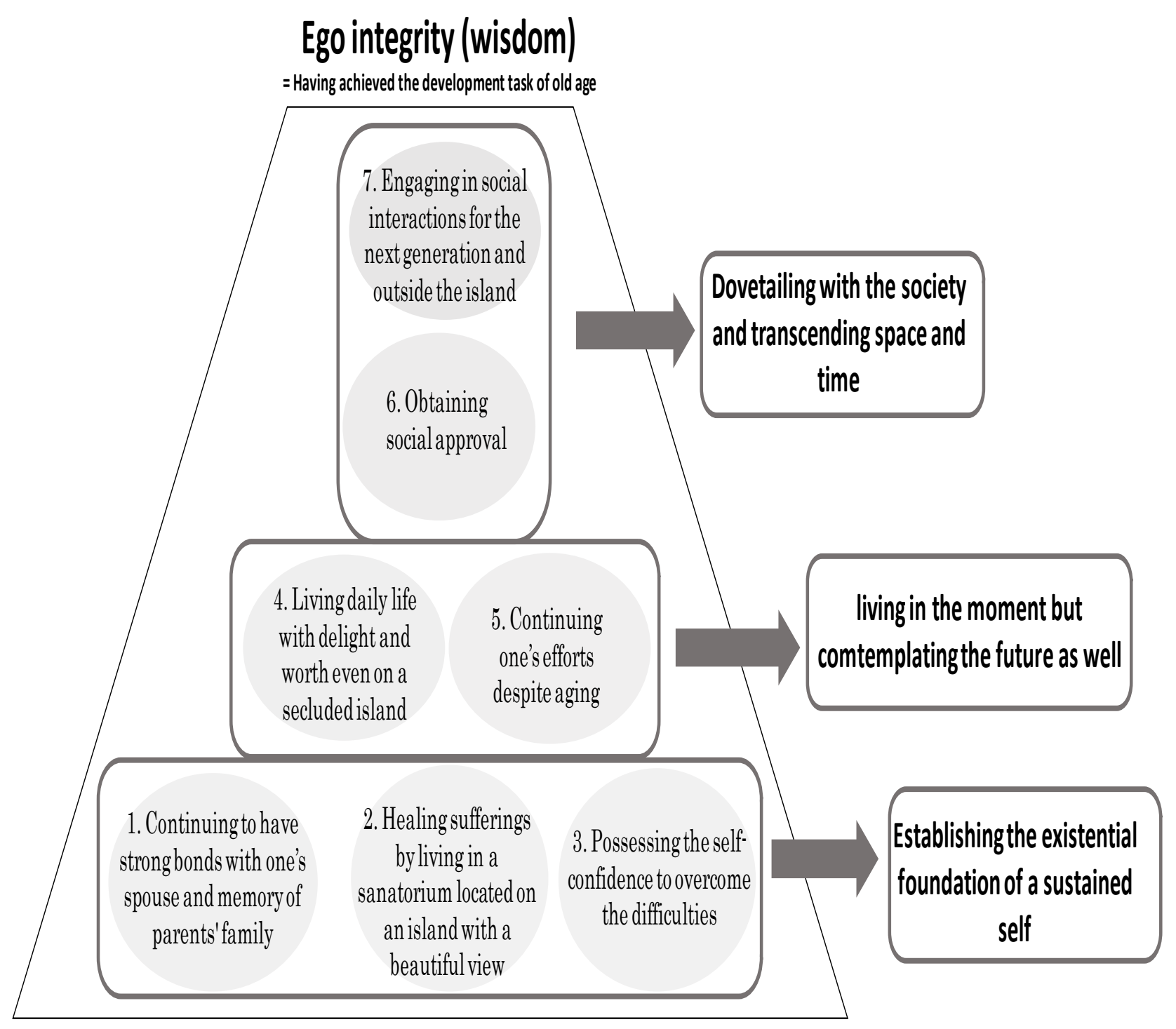

Figure 1: Structure of spiritual well-beingin survivors of Hansen's disease

childhood but also during crises such as being persecuted or discriminated against for having Hansen's disease and entering the leprosarium, and established trust by recalling lasting memories of having received deep affection from their family.

Since ages, Hansen's disease had been deemed as an illness that occurs as a punishment from heaven. By the end of the national crisis of World War II, Hansen's disease was deemed as a national disgrace, and the erstwhile government implemented the Leprosy Prevention Law (Act No. 58, old Rai-yobo-ho) in 1931 to forcibly place patients in a leprosarium. This law recommended the general population to identify patients and inform the police or public health offices to abolish the illness from their prefecture. People felt scared about Hansen's disease, not only because patients had disfigured face and limbs, but also because they were forcibly admitted to leprosariums by the police and their homes were sanitized. Patients could not leave the leprosarium until their death. We think that people's fear against the disease led to the exclusion of and discrimination against patients. Survivors of Hansen's disease who had lived in such difficult situations have memories about being discriminated and bullied, feeling terror or hostility against the public, and, in some cases, continuing to feel the terror or hostility until now. The memory of receiving affection from the family and achievement of trust, which is core of personality formation, helped these patients maintain their psychological health and protect the personality from distortion due to mental trauma, fear, deep grudge, and hatred caused by the discrimination.

Furthermore according to common view, patients with Hansen's disease had cut off their relationship with their family by their own or the family's will to protect the family from discrimination and persecution. As a replacement for their family, patients with fewer sequelae helped those with severe sequelae in their daily life, cared for them in their death bed, and informed their families about their death. Patients with severe problems died without seeing their family members, and they were inhumed within the leprosarium. Even today, though survivors can come back to their native prefecture with the support of their native prefecture office, some refuse to visit their house, see their hometown from the car window, or visit their forefathers' tomb after all their relatives are dead. Possibly, they engage 
in such behavior because they are afraid that their neighbors would remember them and spread new rumors, which would cause their family to suffer again. In this study, three subjects maintained a relationship with their family, but it started only after the law on forceful isolation was abolished. Against common view, this study showed that the family continued to have a place in the survivors' heart, and the family bonds sustained despite aging, and despite the death of their parents.

\section{(2) Intimacy versus Isolation and Generativity versus Stagnation}

The psychosocial crisis at young adulthood is intimacy versus isolation, and the basic virtue is love. A man and woman respect each other's identity and come together. The subcategory $<<5$ ) I shared a deep bond and affection with my spouse because we could not go out into the society and had to live only in the sanatorium $>>$ in the category $<1$. Continuing to have strong bonds with one's spouse and memory of parents' family $>$ shows that the survivors had achieved intimacy.

Because adolescents were susceptible to Hansen's disease, many patients married other patients in the leprosarium. Though the government did not allow pregnancy and childbirth, it allowed marriage. Marriage was allowed to prevent illegal sexual relations, keeping public order in the leprosarium, and enforcing the will of working. The reason for not allowing childbirth was to prevent the spread of the infection to the child and to eradicate Hansen's disease by forced isolation and vasectomy. Thus, the present survivors of Hansen's disease are aged and have no children, due to which the history of Hansen's disease in Japan would end in the near future.

Because survivors cut off relationships with their parents and siblings, and could not have their own children, for these survivors, the family only comprised their spouse. They have lived with their spouse on an island, secluded from the society, with very less support from the government and leprosarium authorities. Thus, they shared their sufferings and overcame difficulties. This strong bond with their spouse enabled the survivors to protect themselves from isolation. In this context, it is important to note that the present sample did not include any unmarried person, while several others in the sanatorium were unmarried. This suggests that spiritual wellbeing may be related to affection with the spouse.

On the other hand, the psychosocial crisis at middle adulthood is generativity versus stagnation, and the basic virtue is care. This developmental task is achieved through child rearing. However, in an attempt to uproot Hansen's disease, vasectomies were conducted, which took away the opportunity from the patients to experience child rearing and achieving this developmental task. Therefore, this treatment was against humanity. However, generativity is not only achieved by child rearing but also by engaging in other activities with the next generation and passing on some knowledge to the next generation. All leprosarium were maintained by the residents themselves, for example, patients engaged in caring for other patients with severe problems, provided nursing assistance for wound treatment, engaged in engineering work, washing clothes, etc. until about 1955. Subsequently, the patients' organization fought against the government and these activities were taken over by sanatorium staff [14]. As patients were not required to work, they had ample free time, which was used for engaging in popular literary, art, music, and sports. Some novels, poems, essays, and humorous seventeen-syllable poems were appraised as high quality literary work and attracted the society's attention. For example Mr. Tamio Hojyo [20], Mr. Kaijin Akasi [21], Mrs. Kazuko Toh [22], etc. These activities are considered to aid the expression of the sufferings of the soul and sublimating them. However, we put forth that patients with Hansen's disease or survivors tried to achieve the developmental task of "Generativity" though their literary work.

\section{(3) Identity versus Role Confusion}

The psychosocial crisis during adolescence is identity versus role confusion, and the basic virtue is fidelity. Identity means understanding "what am I?" The two categories, $<2$. Healing sufferings by living in a sanatorium located on an island with a beautiful view $>$ and $<3$. Possessing the self-confidence to overcome the difficulties $>$ are related to Identity versus Role Confusion.

\section{i) Spiritual pain and its healing}

As described above, Hansen's disease has been stigmatized since ages. Forced confinement and lifelong isolation was mandated by the Leprosy Prevention Law (Act No. 11, Rai-yobo-ni-kansuru-ken, in 1909; Act No. 58, old Rai-yobo-ho, in 1931; Act No. 24, new Raiyobo-ho, in 1953). Therefore, many patients felt despair, and some patients committed or wished to commit suicide because they had accepted discrimination and had abandoned their hopes and dreams about the future23). Sufferings with despair cause spiritual pain or existential suffering, which was also experienced by the survivors of Hansen's disease.

How was their spiritual pain healed? The second category, $<2$. Healing sufferings by living in a sanatorium located on an island with a beautiful view $>$ comprised three subcategories, two out of which, namely, $<<6$ ) Living in a sanatorium is better than living in the society, because the former does not attract discrimination and prejudice $>>$ and $<<8$ ) I was healed by the beautiful view of the sea and islands $>>$ answered this question.

Eight public leprosariums were established in 1909 based on the Leprosy Prevention Law (Act No. 11, Rai-yobo-ni-kansuru-ken). Before setting up public leprosariums, several private facilities existed that were supported by charity. A Sanatorium, where the present study was conducted, was established in 1909 for the homeless patients of this disease, who could not live in their own home town. It was considered the ideal location by the authorities because A Sanatorium is located on a small island, a greater part of which comprises the sanatorium itself. Further, the island is eight kilometers away from mainland, which would deter patients from escaping or would make it easy to identify those trying to escape as the only transportation from the island was by ship. On the other hand, because the island was close to the mainland, the transportation of goods and staff was easy, which facilitated the management of the leprosarium.

The island is located in the inland sea, and has a mild climate and beautiful view. For example the view from the sanatorium comprises the mild and beautiful sea, some islands floating in the sea, white beaches, and green pine trees. By viewing and placing oneself into the nature, residents felt a sense of unity with the nature, and experienced its natural healing power.

The subcategory $<<8$ ) I was healed by the beautiful view of the sea and islands $>>$ shows that the residents' spiritual pain, which was caused by the crushing of their hopes and dreams regarding the future, was healed a little by the nature. This is in keeping with Takeda's concept of spirituality in old age, which includes "harmony with nature" [10].

Secondly, the island represented a clear physical separation from the society. Patients with Hansen's disease had experienced discrimination and persecution from the society. People's fear against Hansen's disease led to the isolation of patients, which was not only rooted in the characteristics of the disease, such as disfigurement of the face and limbs, but was also based in the fear that "if I had Hansen's disease, I might face discrimination, would be separate from my family and admitted to a leprosarium, and will not be able to leave it until my death." Thus, people's fear was stirred up by the implementation of the Leprosy Prevention Law that regulated enforced confinement and lifelong isolation. Although leprosariums had a poor environment because of the lack of support from the government, and patients were forced to do all the jobs, leprosariums functioned as a breakwater protecting patients from persecution by the society. 
The subcategory $<<8$ ) I was healed by the beautiful view of the sea and islands $>><<8$ ) I was healed by the beautiful view of the sea and islands $>>$ show that the leprosarium's environment protected the patients from the society and $<<6$ ) Living in a sanatorium is better than living in the society, because the former does not attract discrimination and prejudice $>>$ assisted the process of healing, leading to spiritual well-being.

ii) Reacquired identity as a person living with Hanse's disease after identity confusion: "Protect us by our own force, without relying on anyone"

Although it is known that patients with Hansen's disease experienced spiritual pain owing to the diagnosis and admission to a leprosarium, it is unclear how they overcame it.

Category $<3$. Possessing the self-confidence to overcome the difficulties $>$ comprised four subcategories, $<<9$ ) I am bright and positive. Therefore, I can overcome problems $>>$; $<<10$ ) I have learnt life lessons that encourage me $>>$; $<<11) \mathrm{I}$ am self-confident because we overcame poverty and World War II $>>$; and $<<12$ ) I am satisfied with my present life because we won justice and have a comfortable life as compared to the enforced work and miserable life of the past $>>$. This category and subcategories show that patients who had already had acquired their identity while living with the society, and had experienced spiritual pain and identity confusion, could overcome the difficulty without help from the leprosarium authorities and the government, and built their own confidence. They reacquired their identity as a person living with Hansen's disease, "protecting themselves with their own force, without relying on anyone."

According to Tanikawa [24], patients with Hansen's disease have overcomepoverty during World War II by building a mature community comprising sub-systems for self-sufficiency, selfdefense, and social security without help from the leprosarium's stuff and the government. Therefore, they continued to have a strong sprit and did not rely on sanatorium staff by setting up survivors' self-government associations and coping with their daily problems. However, as they could not sustain in extreme poverty without working hard, they lost their limbs or eyesight in return for survival, as their injuries worsened during work and caused them to lose their limbs to osteomyelitis. Some also decided to undergo amputation so that they could return to their job as soon as possible in order to sustain their life and that of their spouse or child living out of the island [16].

Thus patients had survived severe poverty by bonding together and by losing limbs as compensation for survival. Even now, the high spirit of having overcome difficulty by one's efforts alone sustained in the aging survivors. By overcoming difficulties, they reacquired a strong identity as person living with Hansen's disease on a limited island, and overcame spiritual pain.

iii) Forming identity as a person living with Hansen's disease without confusion: "Viewing the self as living on a secluded island throughout life"

The subcategory $<<7$ ) I could adapt to living in a sanatorium because I was admitted here when I was a child. At that time, I knew nothing about the society and did not have any ambitions $>>$ under the category $<2$. Healing sufferings by living in a sanatorium located on an island with a beautiful view $>$ showed the formation of an identity as a person living with Hansen's disease "viewing the self as living on a secluded island throughout life" without identity confusion.

Adolescents are susceptible to the disease, and some patients entered the leprosarium at primary or junior high school level. One's objectives and dreams about the future are not clear in childhood, and the development of identity is incomplete. Therefore, it is easier to adapt to a new environment. On the other hand, children's high adaptation protects them from spiritual pain and explains the lower suicide risk as compared to that in adults. It allows them to accept the situation uncritically. According to the oral testimonies of the staff who worked in the old leprosariums that did not respect the patients' dignity, patients who entered the facility in childhood were easy to treat, but those who experienced social life and entered it in adulthood were difficult and rebellious.

One participant reported having the "ambition to go out of the society." The Leprosy Prevention Law that mandated lifelong isolation continued until 1996, but was buffered slowly, after the disease was declared curable by the reintegration of Promin particle candidates into the society. Coming back into the society meant creating one's own future and bringing self-actualization along with the risk that they must work in order to earn a livelihood while being exposed to the society's indifference. The word "ambition" shows that the survivors has to choose whether to continue to live with access to safety, food, clothing, and shelter at the sanatorium, or to live by shouldering responsibilities in the society, which indicates strength, autonomy, and independence.

As mentioned above, the extent to which being diagnosed with Hansen's disease and facing the fact of having to live in a leprosarium for a lifetime bring spiritual pain is influenced identity formation. Children and adolescents, who were yet to form an identity, easily adapted to the new environment of the leprosarium, while adults who had formed an identity experienced fluctuation in their identity and reconstructed a new identity by protecting themselves on their own.

\section{(4) Summary}

The developmental task of old age is ego integrity versus despair, and success in this stage will lead to the virtue of wisdom. Aging survivors of Hansen's disease who live vividly have achieved all developmental tasks; trust, intimacy, and identity. Achieving these tasks promotes the establishment of the existential foundation for the sustained self, and the achievement of ego integrity in old age.

The developmental task of old age is ego integrity versus despair, and success in this stage will lead to the virtue of wisdom. Aging survivors of Hansen's disease who live vividly have achieved all developmental tasks; trust, intimacy, and identity. Achieving these tasks promotes the establishment of the existential foundation for the sustained self, and the achievement of ego integrity in old age.

\section{2) Living in the moment but contemplating the future as well}

The category $<4$. Living daily life with delight and worth even on a secluded island $>$ comprised the subcategories $<<13$ ) I feel joyful and worthy when I cherish my spouse $>>$; $<<14$ ) I feel joyful and worthy while interacting with people on the island, such as fellow survivors, nurses and nurse assistants, and children of the sanatorium's staffs whose school is on the island $>>;<<15$ ) I feel joyful while eating $>>$; and $<<16$ ) Because I must live on a secluded island and feel stifled, I engage in activities to release my energy $>>$. On the other hand, the category $<5$. Continuing one's efforts despite aging $>$ comprised the subcategories $<<17$ ) I invest effort in maintaining health and independence in daily life $>>$ and $<<18$ ) I will continue to learn because I could not learn in childhood because of poverty and discrimination $>>$. We think that these two categories indicate "living in the moment but comtemplating the future as well" The first category pertains to difficulties in having purpose in life and maintaining a relationship between spiritual wellbeing and living in current times. The second is a characteristic of aging survivors of Hansen's disease.

With reference to the first, although survivors can now go out of the sanatorium freely, this was not possible in old times. Patients with Hansen's disease had difficulty in searching for meaning in life because they had to live in a limited space, which they were not allowed to leave until their death (they were also buried in the leprosarium), 
and live with limited relationships with only patients and staffs of the leprosarium. In a psychiatric study on differences between the mental condition of condemned criminals and life imprisoned criminals [25], condemned criminals acted violently, were easily distracted, and stressed, while the life imprisoned criminals exhibited emotional paralysis and regression. The reason for this difference is that while condemned criminals faced their death every day, because the date of execution is notified to the condemned criminal only on the morning of the appointed day, life imprisoned criminals repeat the same daily life until they die. In other words, the life of condemned criminals is condensed to one days, while that of life imprisoned criminals is diluted across his lifetime. Patients with Hansen's disease who could not leave the sanatorium until their death are similar to life imprisoned criminals, as both experience difficulties with delight and hope owing to a repetitive and unchanging daily life. The life review of Mr. Yamamoto [26], an aging survivor of Hansen's disease showed that he had lived idly (gambling without working) for twenty years after entering a leprosarium, although he hoped to study hard to become a doctor before that. Thus, not having a purpose in life on entering a leprosarium diluted the life of patients with Hansen's disease.

In terms of the relationship between spiritual well-being and living in current times, the latter has been observed in cancer patients or in those with an incurable disease, who must live with the awareness of their imminent death. They realize that they may not be alive in future and feel spiritual pain. In the absence of hope for the future and having to live with the awareness of their imminent death, they concentrate on the now and focus on brightening and enhancing the present moment. Focusing on the present and enduring the present to ensure a good future are same things in the context of brightening and enhancing one's life. When dying patients know that they are alive because of something greater than the self, and they focus on the present moment, they overcome spiritual pain, find existential meaning in life, and experience spiritual well-being and a peaceful death. Although the physical function of dying patients deteriorates, they can grow philosophically by achieving spiritual well-being. Thus, they can focus on the present and enrich their lives through the consciousness of their imminent death. Similarly to dying patients, the average age of survivors of Hansen's disease is 82 years. They know little about the rest of their life, and they live in the present whole heartedly.

Regarding the characteristics of aging survivors of Hansen's disease, our study subjects were full of life, younger, had less severe sequalae, and were independent in their daily life as compared to all the residents of the sanatorium. But Dr. Kamiya [27], a psychiatrist and writer, reported that around 1960, patients in a severe condition were full of life, while others in a less severe condition were living idly. Some blind patients with sensory paralysis of limbs learned Braille and read using their tongue even though their tongues bled because of the rough reading surface or the hard paper. Further, they wrote in Braille using a pen with their cheeks because they could not hold the pen by hand owing to motor paralysis or loss fingers or hand. Thus, they had to endure severe hardships to live. On the other hand, patients with less severe conditions were forced to work in the leprosarium, for example they were engaged in nursing for severe patients, providing medical assistance, clean up, conducting funerals, doing engineering work, etc., due to which they did not have leisure time until about 1955 . Owing to such work, their energy was drained. Subsequently, as forced labor reduced gradually with an increase in staff as a result of fighting against the government through patient associations, patients' leisure time increased. Possibly, when Dr. Kamiya visited the leprosarium, all patients were adults, who could have played an active role in the society if they would have not been admitted to the leprosarium. Thus, the task of patients with less severe problems would have been to identify ways to spend their overabundant time and energy, although the tasks for patients with severe problems did not change since they needed assistance.

Currently, the average age of survivors is 82 years. Our subjects had already overcome the tasks of "spending leisure time and using overabundant energy within the limited resources available on the island while waiting for death." Therefore, they reported $<<16$ ) Because I must live on a secluded island and feel stifled, I engage in activities to release my energy $>>$. However, they have been recently experiencing decreasing physical and psychological function owing to aging. Subjects have to adapt to aging and dysfunction. Younger subjects with less severe sequalae and survivors who were independent in terms of activities of daily living had more energy and good health. Therefore, it was easier for them to have a purpose in life as compared to survivors with more severe problems and decreasing physical functioning owing to the multiple and severe sequelae, and aging.

Next, the category 5) <Continuing one's efforts despite aging $>$ comprised the subcategories $<<17$ ) I invest effort in maintaining health and independence in daily life $>>$ and $<<18$ ) I will continue to learn because I could not learn in childhood because of poverty and discrimination $>>$. This category shows that the subjects continued to invest effort to maintain their independence and autonomy despite the decreasing physical function owing to aging. In addition, they continued to learn. Receiving education at a young age often leads to social success, for example, securing admission in a university and securing qualifications. It is sometimes supported by extrinsic motivation. On the other hand, for aging survivors, learning does not lead to social success, but is supported by intrinsic motivation and the joy of learning. Many survivors of Hansen's disease did not receive formal education in childhood because they could not venture out of their houses to avoid public eye or to avoid forced admission into a leprosarium. Additionally, some were expected to peregrine like a pilgrim because they could not live in their home town owing to severe discrimination and expulsion. At the leprosarium, teachers were often patients themselves. Some aging survivors had the hunger to learn, and engaging in learning now, they tried to fulfill their craving and achieve added tasks.

\section{3) Dovetailing with the society and transcending space and time}

Category $<6$. Obtaining social approval $>$ and the fact that all subjects had a role in the sanatorium show that social approval is important for living as social beings. Category $<7$. Engaging in social interactions with the next generation and outside the island $>$ shows that the survivors attempted to recover their relationship with the society and the next generation. They attempted to cross the boundaries of a small island and sought social approval for having survived in extreme situations, which is important for achieving selfactualization.

Maslow's Hierarchy of Needs[28] puts forth that needs are fulfilled from lower needs to higher needs, i.e., from physical needs to safety needs, followed by the need for love/belonging, self-esteem, and self-actualization. While the first four needs are called as deficiencyneeds, the fifth pertains to achieving self-transcendence. Patients with Hansen's disease patients could not fulfill even basic physical and safety needs in the old leprosariums, which threatened their human rights, or when they led a nomadic life. Subsequently, their life situation improved gradually and they could fulfill their physical and safety needs. Their need for love/belonging was fulfilled by their good memories of parents and family members, although their relationships were cut off by them or their relatives to prevent discrimination (see above). The love/belonging need was also fulfilled by the affection of the spouse with the disease, although they did not have their own child, and by helping each other through activities such as establishing survivors' associations based on mutual love and support. 
Further, the category $<6$. Obtaining social approval $>$ also contributes to fulfilling the survivors' esteem needs. All the selected subjects lived with vigor and played a role in the sanatorium. A role is defined as a pattern of behaviors acquired when one person participates in a social system and hold a position in the social system. This behavior, in interaction with that of others, leads to role pairing or the role pair system [29]. Aging survivors of Hansen's disease faced incarceration and lifelong isolation since childhood or young adulthood, and they lost the right to live in a society. Having a role to play on a small island compensated for not being able to fulfill responsibilities in the general society. Thus, the survivors recognized the self as a social being and their self-esteem was enhanced.

Furthermore, category $<7$. Engaging in social interactions with the next generation and outside the island $>$ strengthened their esteem and aided self-actualization. In 1996, the Leprosy Prevention Law was abolished, the court recognized mistakes of the medical policy under the law, and government officially apologized to survivors of Hansen's disease. In 2009, the Act to Accelerate the Resolution of Problems of Hansen's Disease (Act No. 82, Hansenbyomondai no kaiketsu no sokusinnikansuruhoritsu) was implemented [30]. The new law guarantees not only being free to live in a sanatorium for the rest of their life and supplying suitable medicines, but also supports the survivors to reintegrate themselves into the society, or promotes their interactions with the society, recovery of the honor of survivors, mourning the bereaved patients, and supporting them to build a family. Since the implementation of this new law, many general people have been visiting sanatoriums to learn about human rights, and survivors a free to leave the island and be accepted in the society. The subcategories $<<21$ ) Communication with relatives included not only my parents and siblings but also my sibling's spouse, nephew, and niece $>>$ and $<<22$ )Though my interaction with the society was broken off, my social interactions and activities started again and increased due to my spouse's encouragement $>>$ showed that the survivors intended to mend the broken relationships with relatives and communicate with the next generation. The subcategories; $<<24$ ) Our supporters' children have become our new supporters, thus continuing the work across generation $>>$; and $<<25$ ) I could be known as a person living with Hansen's disease and my interactions with those outside the island could increase because the press or media would want to report my experience with Hansen's disease $>>$ showed that the scope of living as social being had spread from the small island to the general society, and survivors found a new role as a storyteller about the history of Hansen's disease. Being accepted and approved by the general society brings joy to the survivors and promotes them to form a new identity. In other words, sharing their past experiences is a way of contributing to the general society. When they change from an oppressed person to a contributor in the society, the real recovery of their human rights is realized. They acquire a new identity as a person who has survived extreme experiences and who can contribute to the society. This promotes self-actualization. However, we must remember that very few survivors live their life vividly, and for many the recovery of their human rights is too late.

\section{Universal Application Beyond Hansen's Disease}

In this study, we explored the questions "How do individuals live energetically despite having experienced extreme situations?" and "How do they maintain spiritual well-being?" A characteristic feature of the survivors of Hansen's disease in the present study was the formation of a strong and stable existential foundation by achieving developmental tasks. In this sample, the deformation of personality owing to their experiences of discrimination and persecution was small. Why can the create a stable existential foundation despite having a deficient life, for example losing the relationship with their family of orientation, not having their own child, and not playing an active part in the general society. We think that their life involved some compensatory action. For example, although they are cut off from their family of orientation, they continued to connect with their family through fond memories. Although they did not have children of their own, they continued to engage in creative activities. Although they did not playing an active part in the general society, they shouldered several responsibilities in their small community on the small and secluded island.

In general, we cannot achieve all that we seek, and cannot escape the loss of significant persons and things. However, it is important to engage in compensatory actions in a constructive way when faced with difficulties, which fosters the achievement of the developmental task of ego integrity during aging. However, the feeling of suffering owing to the loss cannot be avoided through compensatory action. According Erikson [19], if old persons can compensate for the insufficiency of each stage, they can reach "gerotranscendence." Our subjects exhibited this phenomenon.

\section{Limitations of the Study}

One limitation of this study is the small sample size. However, this was inevitable because we included only those subjects who lived with vigor and liveliness, and strictly excluded those with dementia, which comprised $32 \%$ of the population at A sanatorium [18]. Because the number of survivors of Hansen's disease is decreasing rapidly owing to aging, we must expedite the process of understanding their experiences and passing them down to the next generation. This is our last chance. Thus, this study is an important historical study.

Second, the narrative data in this study did not explore religion, although four of the subjects were Buddhists and one was Christian. Spirituality is different from religion, but it is easy for religious persons to experience spirituality in daily life. Psychiatrist Dr. Kamiya [23] reported that a few patients with Hansen's disease sought solace in religion. In the old times, because patients could not leave the leprosarium until death, the leprosarium had religious spaces of various religious organizations. This suggests that patients with Hansen's disease were "healed" by religion. But why did contents related to religion not appear our study? The first possibility is that the subjects of the study did not need salvation by God or Buddha because they overcame their sufferings and felt peaceful. The second possibility is that administrators of old leprosariums registered the patients' religious denomination as passed on from their father. Many Japanese are not monothrism, and religion is merely used for ceremonial purposes, for example in funerals and weddings. Our findings show that the aging survivors do not attach importance to religion.

\section{Conclusion}

The spiritual well-being of aging survivors of Hansen's disease is integrated into 7 categories, and shows a trilaminar structure comprising establishing the existential foundation for the sustained self, living in the moment but contemplating the future as well, and dovetailing with the society and transcending space and time. They were found to have achieved the ego integrity developmental task of old age.

In this study, we discussed "How do individuals live energetically despite having experienced extreme situations?:through the experiences of aging survivors of Hansen's disease in Japan. We suggest that, by functioning compensatory mechanism, we may be able to achieve developmental tasks even if we are faced by adverse conditions like not having significant others related to developmental tasks. If compensatory mechanism is met, we might be able to develop an existential foundation for the sustained self and achieved ego integrity at old age despite having to live in unfortunate circumstances. Thus, if we support such individuals, we can promote compensatory mechanism. Secondly, we suggest that persons who experienced discrimination, which led to poor self-esteem, do not need approval from society, but dovetailing with the society 
and transcending space and time aids the recovery of their dignity. Therefore, we can support them through providing human rights education and involving the next generation.

\section{Acknowledgements}

We wish to thank the participants of this study. This study was supported by JSPS KAKENHI Grant Number 15K15797.

Conflict of Interest: The authors of this paper have no conflicts of interest to report.

Author Contributions: All the authors are contributed equaly References

1. Kotera S (ed) (2015) Reading again by Yamakawa series; philosophy. Yamakawa Shuppansha Ltd., Tokyo, Japan.

2. Fujii M (2010) Essential of spiritual care - From point of view of thanatology. Jpn J Gerontol 31: 522-528.

3. Frankl VE (2006) Man's search for meaning. Beacon Press, Place of Publication.

4. Fujii M. (2000) Quality of life and spirituality. KwanseiGakuinSociol Department Stud 85: 33-42.

5. Haas BK (1999) A multidisciplinary concept analysis of quality of life. West J Nurs Res 21: 728-742.

6. NANDA International(2014) Nursing Diagnoses 2015-17: Definitions and Classification (10th ed), Wiley-Blackwell,USA

7. Kawa M, Mizuno M, Kayama M (2001) Construction of theoretical basis about spiritual care for terminal ill patients. Results Report of Grant- in-Aid for Scientefic Research C by Japan Society for Promotion of Science.

8. Okamoto N (2013) The concept of spiritual well-being in the elderly and its characteristics. Kawasaki Med Welf J 23: 37-48.

9. Misawa H, Nojiri M, Niino N (2010) Spirituality rating scale for the elderly in community-a study of validity and reliability-. J Jpn Health Med Asso 18: 170-180.

10. Takeda K, Futoyu Y, Kirino M, Kumo K, Kim JS, et al., (2007) Development of a spirituality rating scale related to health in the elderly-A study of the validity and reliability. J JpnAcad Health Sci 10: 63-72.

11. Ohtani F, Saito H, Nagao E, Murakami K (ed.) (1997) Hansen' s disease medical science. Tokai University Press, Kanagawa, Japan.

12. U.S. Department of Health and Human Services, National Institutes of Health. Leprosy (Hansen's disease) - A history of the disease.

13. Yamamoto S (1993) The Japanese History of Hansen's disease. University of Tokyo Press, Tokyo, Japan.

14. National Hansen's disease Sanatorium Residents' Council(2002) Records of fighting by National Hansen's disease Sanatorium Residents' Council (reprinted). Ikkosha, Place of publication.

15. OshimaSeisho-en (1960) 50 years of history at the national sanatorium in OshimaSeisho-en. OshimaSeisho-en, Place of publication.

16. Yamaberi M, Kondo M, Ishikawa K, Amano Y, Kondo M (2015) Causes of and coping strategies for repeated wounds in patients with Hansen's disease until Promin treatment. J Jpn Soc Nurs Res 38: 59-71.

17. Japan Law Foundation. Final reports - verification meeting about Hansen's disease problems.

18. Tsukimori K (2015) Appendix Future vison and tasks on National Sanatorium OshimaSeisho-en, 543-552 pp. Kondo $\mathrm{M}$, Oshimaseisho-en(Ed): Life review of Hansen's disease survivors living in Oshimaseisho-en, Kazamashobo, Tokyo, Japan.
19. Erikson EE (1994) Identity and the life cycle. WW Norton \& Co. Inc., New york, USA.

20. Hojyo T (1955) The first night of life. KadokawaShoten, Tokyo, Japan.

21. Akashi K (2012) Anthology of Kaijin Akashi. Iwanami Shoten, Tokyo, Japan.

22. Toh K (2004) Anthology of Kazuko Toh. Henshu-Kobo Noa, Osaka, Japan.

23. Kamiya M (1973) Person living into extreme state-being with leprosy patients. Rugal company, Kyoto, Japan.

24. Tanikawa T, Miyawaki H, Shinjyo H, Amamo Y, Kondo M (2016) The meaning of experience in the everyday poverty for the oldest Hansen's disease survivors - Through the narratives of residents admitted around World War II into a leprosarium in the Seto Inland sea. Jpn J Lepr 84: 37-50.

25. Kaga O (2008) Psychology of condemned criminal and imprisonment for life. Kongoshuppan, Tokyo, Japan.

26. Yamamoto T, Yamaberi M (2015) Chap 3 Life review of Takahisa yamamoto, 85-86, Kondo M, Oshima sesho-en (Ed): Life review of Hansen's diseases survivors living in Oshima seisho-en, Kazama shobo, Tokyo, Japan.

27. Kamiya M (1980) About sense of purpose in life Misuzu Shobo, Tokyo, Japan.

28. Maslow AH (1987) Motivation and personality ( translated version) Sanno Institute of Management Publication Dept, Tokyo, Japan.

29. Oda M (2016) Understading Practice about Roy's Adaptation model. Igaku shoin, Tokyo, Japan.

30. Ministry of Health Labor and welfare (2008) Act to Accelarate the Resolution of Problems of Hansen's Diseases. 